\title{
Size selectivity of redfish (Sebastes spp.) in the Northeast Atlantic using grid-based selection systems for trawls
}

\author{
Bent HerRmanN ${ }^{1, a}$, Manu Sistiaga ${ }^{2}$, Roger B. LARSEN ${ }^{3}$ and Kåre N. NIELSEN ${ }^{3}$ \\ 1 SINTEF Fisheries and Aquaculture, Fishing Gear Technology, Willemoesvej 2, 9850 Hirtshals, Denmark \\ 2 SINTEF Fisheries and Aquaculture, Brattørkaia 17C, 7010 Trondheim, Norway \\ 3 University of Troms $\varnothing$, Breivika, 9037 Troms $\varnothing$, Norway
}

Received 21 November 2012; Accepted 28 March 2013

\begin{abstract}
Using experimental data and a model to predict size selection based on morphological data, we investigated size selection of redfish (Sebastes spp.) in the grid-based selection systems used in Northeast Atlantic trawls. We found that not all redfish make physical contact with the spacing between the bars in the sorting grids while they pass in the direction of the codend, and therefore the escapement of some undersized redfish depends on size selection in the codend. We estimate that most of the escapement in the combined selection system (consisting of a 55-mm grid and a diamond mesh codend) happens through the grid. We demonstrated that for one of the two grid systems investigated the increase in size selection obtained experimentally by increasing grid-bar spacing is well in line with what could be expected based on the morphology of redfish. However, the size selection observed experimentally was significantly lower than the size-selective potential of the grids estimated based on the morphology of redfish. By computer simulations, we show that a possible explanation for this difference could be that not all redfish that attempt to escape through the grid make their attempt with an optimal angle of attack.
\end{abstract}

Keywords: Trawl fisheries / Fishing gear / Sorting grid system, Selectivity / Angle of attack / Redfish / Sebastes

\section{Introduction}

Redfish (Sebastes spp., Scorpaeniformes) are important commercial species in the North Atlantic. Three species are exploited commercially in this area: Sebastes marinus, Sebastes mentella and Sebastes fasciatus. Although each species has distinguishing features, they are so similar in shape and appearance that it is often difficult to differentiate them unless they are carefully examined (Power and Ni 1985; Pampoulie and Danielsdottir 2008). In the International Council for the Exploration of the Sea (ICES) subareas I and II (Norwegian Sea and Barents Sea), S. marinus and S. mentella are the two most important commercial species. These species have been widely exploited in these areas in recent decades, but the situation for some stocks calls for stricter management regimes in the near future. For example, for $S$. marinus in 2013, ICES advised "that there should be no fishery, given the very low spawning stock biomass (below any possible reference points) and poor recruitment" (ICES 2012). The situation for $S$. mentella, however, seems better. Based on the maximum sustainable yield approach, ICES advised that a commercial fishery for $S$. mentella in subareas I and II can take place if catches (including bycatches and discards) do not exceed 47000 tonnes.

\footnotetext{
${ }^{a}$ Corresponding author: bent.herrmann@sintef.no
}

In the North Atlantic, most redfish is captured by pelagic and bottom trawls in relatively deep waters (most often $>200 \mathrm{~m}$ ) (ICES 2011). Aiming at improving the selective properties of trawls, Norwegian researchers developed a sorting grid called Sort-X, which was installed as the section preceding the diamond mesh codend (Fig. 1a,b) (Sistiaga 2010). This grid became mandatory for trawlers in 1997. The Sort-X grid consists of two stainless steel grid sections (areas: 1.35 and $1.07 \mathrm{~m}^{2}$ ) and a third canvas-covered steel frame section. Although most fish are expected to contact at least one of the two grids, some fish swimming along the lower panel in the trawl would be able to pass through the grid section without contacting either of the two grids on their way towards the codend. Due to the difference in angle and position of the two grids, the angle of attack for fish attempting to pass through the two grids may differ. Based on the working principles of the Sort-X grid system, Russian researchers developed the Sort-V grid system (Fig. 1a,c). This grid structure is also constructed of stainless steel but has only one grid piece (area: $1.42 \mathrm{~m}^{2}$ ). In contrast to the Sort- $\mathrm{X}$, the Sort- $\mathrm{V}$ includes a lifting panel to guide the fish towards the grid as they pass towards the codend. The Sort-V was made legal for use in Norwegian waters in 2000. Shortly after this, a new plastic and rubber grid construction called Flexigrid, intended to be more user friendly, was designed in Norway. This grid offers the advantage of 
a.

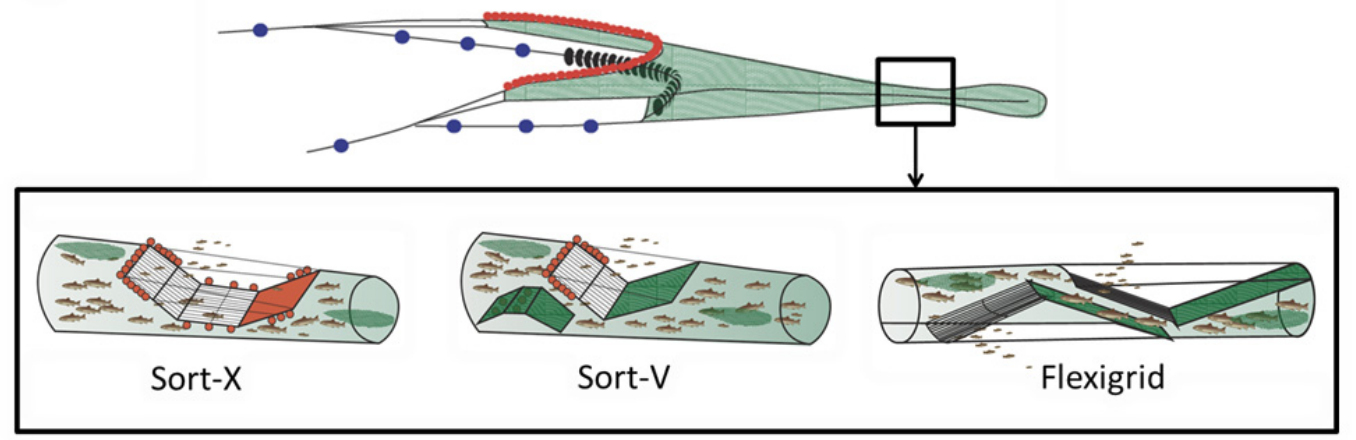

b.

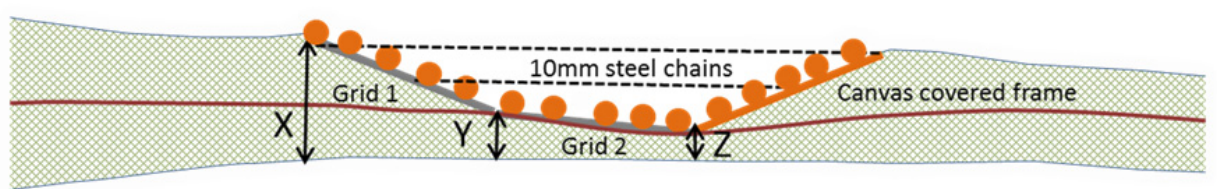

C.

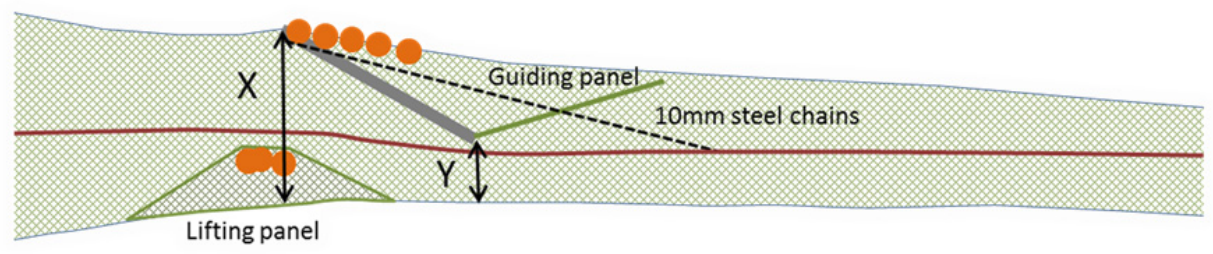

Fig. 1. (a) Legal grids for the Northeast Atlantic bottom trawl fishery. (b) Details of the Sort-X system (Grid 1: $1.35 \mathrm{~m}^{2}$, angle $18-22^{\circ}$; Grid 2: $1.07 \mathrm{~m}^{2}$, angle $5-8^{\circ}$; Opening heights at $\mathrm{X}, \mathrm{Y}$ and $\mathrm{Z}$ are estimated to be $1000-1200 \mathrm{~mm}, 300-400 \mathrm{~mm}$ and $100-150 \mathrm{~mm}$, respectively; 200-mm PL floats are used). (c) Details of the Sort-V systems (Grid: $1.42 \mathrm{~m}^{2}$, angle 20-23 ; Opening heights at X and Y are estimated to be 1100-1300 mm and 150-250 mm, respectively; Both the guiding panel and the lifting panel are constructed in 60-mm netting; 200-mm PL floats are used).

being light and flexible and, due to its neutral buoyancy, it does not require floats or chains (Angell 1999) (Fig. 1a). The use of this system in the Barents Sea was permitted in 2002.

Today, all three grid systems are permitted in the Barents Sea, provided that the grid-bar spacing is at least $55 \mathrm{~mm}$. In addition to the compulsory grid, the regulations in the area state that all codends used must have a minimum diamond mesh size of $130 \mathrm{~mm}$. The combination of a sorting grid and a sizeselective diamond mesh codend is also used in other areas in the North Atlantic, such as in Icelandic waters. Here, grids are used with a bar spacing of $55 \mathrm{~mm}$ in the cod fishery, where redfish is an important bycatch species (Haraldur Einarsson IMR, Iceland, pers. comm.). The cod fishery is one of the most important fisheries in Iceland, and the bycatch of redfish can at times be considerable. Therefore, it is highly relevant to quantify the size-selective properties of these grid-based selective devices with respect to redfish.

While the size selection of redfish in diamond mesh codends is well understood and quantified (Herrmann et al. 2012), the performance of grid-based selection systems in terms of redfish selection is not well documented. Therefore, the aim of this study was to investigate the size-selective properties of two grid-based selection systems (Sort-X and Sort-V) with respect to size selection of redfish. Specifically, we addressed the following questions:

- Do all redfish that encounter attempt to escape through the grid and how good are they at contacting the grid with an optimal angle of attack?

- How do the size-selective properties of the grid depend on the bar spacing?

- How much of the total escapement in the combined selective system is attributable to the grid and what is the balance between the release potentials of the currently used grid and codend?

- Can the size-selective potential of different grid-bar spacing be understood based on fish morphology?

To investigate these questions, we used experimental fishing data from two different cruises, as well as morphology-based experimental data.

\section{Materials and methods}

\subsection{Collection of experimental selectivity data}

The redfish selectivity data included in this study was collected off the Norwegian coast during two cruises, one in 1992 
a.
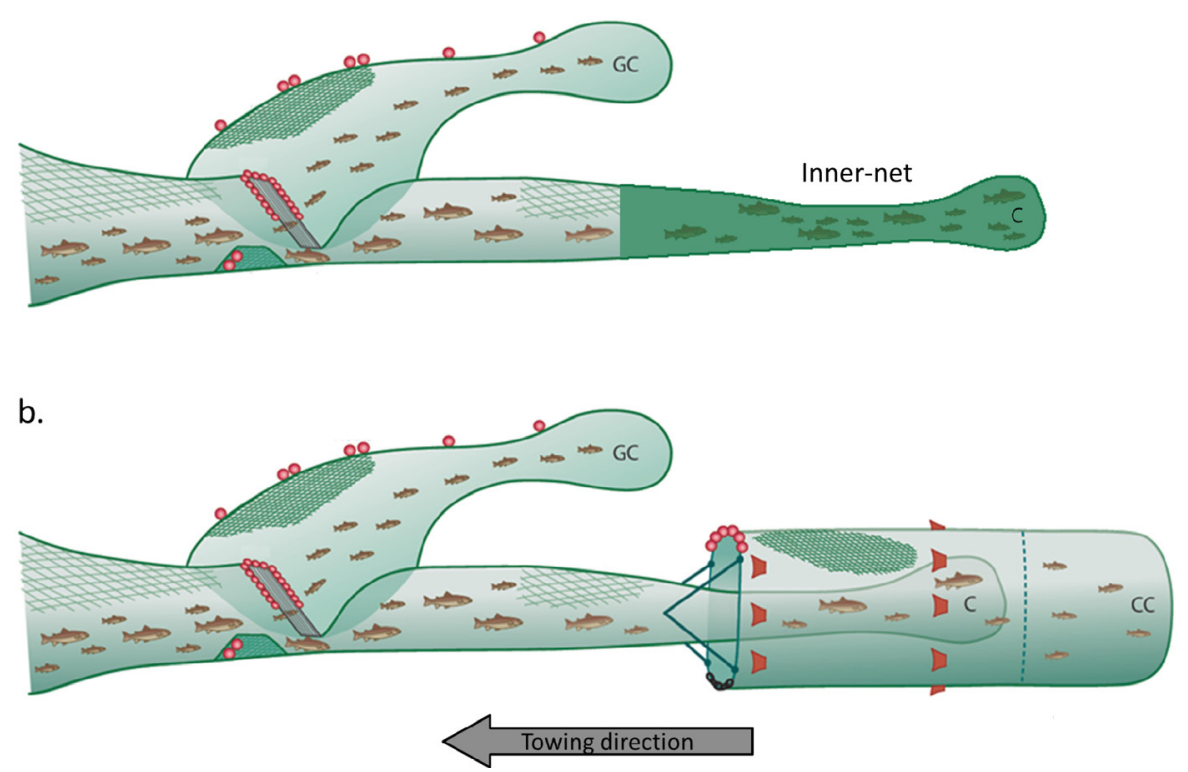

Fig. 2. Experimental setups (both illustrated with the Sort-V grid). (a) Grid + codend setup where a cover (GC) collects the fish escaping through the grid and the codend (C) is blinded with an inner net. (b) Grid + codend setup where a first cover (GC) collects the fish escaping through the grid and a second cover (CC) collects the fish escaping through the codend meshes (C).

and another in 2009. Two different experimental designs were used to collect the selectivity data (Fig. 2).

\subsubsection{Cruise onboard the M/V Prestfjord}

The cruise onboard the M/V Prestfjord (57 m total length, and 3000 HP) took place in March 1992, with the third author of this study in charge of data collection. The data were collected using an Alfredo no 4 trawl, which had an 18.9-m fishing line and was entirely constructed of 135 -mm meshes. During the trials, the selectivity of $40-\mathrm{mm}, 45-\mathrm{mm}$, and $50-\mathrm{mm}$ bar spacing grids inserted in the Sort-X sorting grid system (Fig. 1) was measured for redfish using the experimental design in Figure 2a. A cover retained the fish escaping through the grid, whereas the fish that did not manage to escape through the grid were collected in a 52-mm diamond mesh codend $(52-\mathrm{mm}$ codend was considered non-selective for the size ranges of interest). Two, three, and twelve hauls were conducted for the 40-mm, 45-mm, and 50-mm grids, respectively. The redfish collected in the cover and codend were measured to the nearest centimetre, and in some cases the catch was subsampled. The redfish measured during this cruise were classified as Sebastes spp. because they were a mixture of $S$. mentella and S. marinus.

\subsubsection{Cruise onboard the R/V Jan Mayen}

Data collection onboard the $R / V$ Jan Mayen (64 m length overall, and 4080 HP) was done in March 2009, with the second author of this study in charge of data collection. The trawl used in this trial was an Alfredo no 5 trawl, constructed of 155-mm meshes (the top front panel and the wings were built of 200-mm meshes). The selection system installed in the trawl was a Sort-V grid combined with either a $135-\mathrm{mm}$ codend (setup 1) or a 140-mm codend (setup 2). Both the grid and the codend were covered with a sampling net that collected the fish escaping from the grid and the codend (experimental design in Fig. 2b). This setup enabled an evaluation of a possible dual selection process in the grid and codend system. The covers used over the grid and the codend are described in Sistiaga et al. (2009). Eleven hauls were carried out with setup 1, and six with setup 2 .

\subsection{Modelling size selection for individual hauls with the Sort-X grid}

The data used to assess the size selectivity of the Sort-X grids with different bar spacing were collected using the design shown in Figure 2a. For individual hauls separately, we had information on the number of redfish $n_{\mathrm{gcl}}$ counted in the grid cover $\mathrm{GC}$ and the number $n_{\mathrm{cl}}$ counted in the non-selective codend $\mathrm{C}$ for each length class $l$. In addition, we had information for each individual haul on the length-independent subsampling fractions $q_{\mathrm{gc}}$ and $q_{\mathrm{c}}$ for the redfish in the grid cover and in the non-selective codend, respectively. The available size selection $r_{\mathrm{a}}(l, v)$ (Millar and Fryer 1999) for the grid system in individual hauls can be estimated by minimizing the negative log likelihood function (1) with respect to the parameter $\boldsymbol{v}$ describing the function $r_{\mathrm{a}}(l, v)$ :

$$
\begin{aligned}
& -\sum_{l}\left\{n_{\mathrm{cl}} \times \ln \left(\frac{q_{\mathrm{c}} \times r_{\mathrm{a}}(l, v)}{q_{\mathrm{c}} \times r_{\mathrm{a}}(l, v)+q_{\mathrm{gc}} \times\left(1-r_{\mathrm{a}}(l, v)\right)}\right)\right. \\
& \left.\quad+n_{\mathrm{gcl}} \times \ln \left(\frac{q_{\mathrm{gc}} \times\left(1-r_{\mathrm{a}}(l, v)\right)}{q_{\mathrm{c}} \times r_{\mathrm{a}}(l, v)+q_{\mathrm{gc}} \times\left(1-r_{\mathrm{a}}(l, v)\right)}\right)\right\} .
\end{aligned}
$$


The summation (Eq. (1)) is performed over length classes. An appropriate model for the size selection $r_{\mathrm{a}}(l, v)$ must be found. An inspection of the Sort-X design (Fig. 1) reveals some fish could actually swim underneath the two grid sections without coming into contact with any of the grids. The redfish that did not contact the grid would all be collected in the codend (due to the inner net). A redfish that contacts at least one of the two grid sections, has a length-dependent probability of being able to pass through the grid and end up being collected in the grid cover (Fig. 2a). This probability will depend on its size and shape compared with the grid-bar spacing and on the lateral orientation of its body relative to the bars of the grid. For the redfish that contact the grid, we assume that the length-dependent retention probability can be sufficiently well modelled by a logit function (Wileman et al. 1996) defined by the parameters $L 50_{\text {grid }}$ and $S R_{\text {grid }}$. Because some fish might not come into contact with the grid, we propose the following model, called clogit, which estimates the available size selection for the Sort-X system:

$$
\begin{aligned}
r_{\mathrm{a}}(l, v) & =\operatorname{clogit}\left(l, L 50_{\text {grid }}, S R_{\text {grid }}, C_{\text {grid }}\right) \\
& \equiv 1-C_{\text {grid }} \times\left(1-\operatorname{logit}\left(l, L 50_{\text {grid }}, S R_{\text {grid }}\right)\right) .
\end{aligned}
$$

In the clogit function, $C_{\text {grid }}$ represents the probability that fish entering the grid zone will contact at least one of the two grid sections of the Sort-X grid system. Thus, $0 \leqslant C_{\text {grid }} \leqslant 1$, if $C_{\text {grid }}=1$, every fish entering the grid area will contact at least one grid section, and equation (2) simplifies to the logit function.

$L 5 O_{\text {grid }}$ is the $L 50$ value for the proportion of fish that contacts the grid, whereas the available $L 50\left(L 50_{a}\right)$ is the value for the fish entering the grid area, including the fish that do not contact the grid. Similarly, we distinguish between the selection range for those fish contacting the grid $\left(S R_{\text {grid }}\right)$ and those fish entering the grid area but not necessarily contacting the grid $\left(S R_{\mathrm{a}}\right)$. Since redfish individuals of different size are expected to differ in terms of swimming ability, reaction time and other behavioural factors that could affect grid contact probability, it seems likely that the value for $C_{\text {grid }}$ would be length dependent. However, we initially assumed that considering $C_{\text {grid }}$ length independent is a reasonable approximation and only considered a more flexible model if the lengthindependent assumption led to a model that was unable to adequately describe the experimental data.

Equation (2) was used to model the size selectivity for the individual hauls conducted with the Sort-X grids. For comparison, we tested whether the standard logit function modelled the data better. This comparison was based on fit statistics ( $p$-value and model deviance vs. the degrees of freedom for the two models (see Wileman et al. 1996). In addition, we calculated the Akaike information criterion (AIC) value (Akaike 1974) for each model and determined whether the increased complexity introduced by the additional parameter in equation (2) could be justified considering the simplicity of the logit model. Thus, if equation (2) produced a lower AIC value than the logit model for more than a few hauls, then equation (2) should be selected, because the logit model can be regarded as a special case of equation (2) (when $C_{\text {grid }}=1$ ).

Based on $L 50_{\text {grid }}, S R_{\text {grid }}$, and $C_{\text {grid }}$, the available selection parameters $L 50_{\mathrm{a}}$ and $S R_{\mathrm{a}}$ can be calculated using formula (2) and the definitions for $L 50$ and $S R$ (see Wileman et al. 1996). To calculate $L 50_{\mathrm{a}}, r_{\mathrm{a}}(l, v)$ is set to 0.5 and $l$ to $L 50_{\mathrm{a}}$, and then $L 50_{a}$ is isolated in equation (2). The approach is similar to calculating $L_{75 \mathrm{a}}$ and $L_{25 \mathrm{a}}\left(S R_{\mathrm{a}}\right.$ is then calculated as the difference between these). $L 50_{\mathrm{a}}$ and $S R_{\mathrm{a}}$ can, based on the above procedure, be expressed by:

$$
\begin{aligned}
L 50_{\mathrm{a}} & =\frac{S R_{\text {grid }} \times \ln \left(2 \times C_{\text {grid }}-1\right)}{\ln (9)}+L 50_{\text {grid }} \\
S R_{\mathrm{a}} & =\frac{S R_{\text {grid }} \times \ln \left(\frac{3 \times\left(C_{\text {grid }}-0.25\right)}{\left(C_{\text {grid }}-0.75\right)}\right)}{\ln (9)} .
\end{aligned}
$$

Here, $S R_{\mathrm{a}}$ becomes undefined if $C_{\text {grid }}<0.75$ because the retention probability cannot then reach a value as low as 0.25 .

The model used (Eq. (2)) is similar in structure to the one applied by Zuur et al. (2001) and O'Neill et al. (2006) for estimation of the available size selection for square mesh panels inserted in a trawl.

The analysis was conducted using the software tool SELNET (Herrmann et al. 2012).

The estimation of the $3 \times 3$ covariance matrix for $L 50_{\text {grid }}$, $S R_{\text {grid }}$, and $C_{\text {grid }}$ for individual hauls was based on applying a bootstrap technique similar to the method described for individual hauls in Millar (1993). Applying the standard parametric method based on the calculation of the Fisher Information Matrix (Wileman et al. 1996) would not be valid for hauls where $\mathrm{C}_{\text {grid }}$ is estimated to have a value close to one of the boundaries ( 0 or 1$)$, after Collins and Lanza (2010). The estimation of confidence limits for $L 50_{\text {grid }}, S R_{\text {grid }}, C_{\text {grid }}, L 50_{\text {a }}$ and $S R_{\mathrm{a}}$ was therefore also based on the bootstrap method described by Millar (1993) using the "Efron percentile 95\%" confidence limits (Efron 1982; Chernick 2007), and 10000 bootstrap repetitions were carried out for each haul.

\subsection{Modelling the effect of the Sort-X grid-bar spacing on size selection}

Based on equation (2), the size selection in the individual hauls is described by three parameters: $L 50_{\text {grid }}, S R_{\text {grid }}$, and $C_{\text {grid. }}$. Besides being affected by the grid-bar spacing used in the individual hauls, the size-selection process is expected to be subjected to between-haul variation (Fryer 1991). To model the between-haul variation in the size-selection process while accounting for grid-bar spacing as a fixed effect, we applied the method developed by Fryer (1991). In addition to values for the three selection parameters from individual hauls, the method requires the $3 \times 3$ covariance matrix for the selection parameters from the individual hauls as input. To account for grid-bar spacing as a fixed effect, Fryer's method (1991) also requires a model for the effect of bar spacing on the three selection parameters. The starting point for model (4) was the assumption that $L 50_{\text {grid }}, S R_{\text {grid }}$, and $C_{\text {grid }}$ can potentially be linearly dependent on the grid-bar spacing $b$ :

$$
\begin{aligned}
L 50_{\text {grid }}(b) & =p_{01}+p_{11} \times b \\
S R_{\text {grid }}(b) & =p_{02}+p_{12} \times b \\
C_{\text {grid }}(b) & =p_{03}+p_{13} \times b .
\end{aligned}
$$


The parameters $p_{01}, p_{02}$ and $p_{03}$ represent the intercept terms in the model and $p_{11}, p_{12}$ and $p_{13}$ represent the slopes for the effect of bar spacing (see Fryer 1991). Besides model 4, we also considered all the simpler models that can be derived by eliminating either one or more of the terms at a time. Among all the potential models, the one that produced the lowest AIC value was selected. The resulting model was used to predict the effect of grid-bar spacing on $L 50_{\text {grid }}, S R_{\text {grid }}$, and $C_{\text {grid }}$. The resulting model's ability to describe the results from individual hauls was checked by plotting the results from individual hauls with confidence limits against the values predicted by the resulting model while accounting for the predicted betweenhaul variation in the size-selection process. The lower and upper $95 \%$ confidence limits for the estimated between-haul variation in the selection parameters $\left(\lim L 50_{\text {grid }}, \lim S R_{\text {grid }}\right.$, and $\lim C_{\text {grid }}$ ) for grid-bar spacing $b$ are calculated by:

$$
\begin{aligned}
\lim L 50_{\text {grid }}(b) & =L 50_{\text {grid }}(b) \pm 1.96 \times \sqrt{D_{11}} \\
\lim S R_{\text {grid }}(b) & =S R_{\text {grid }}(b) \pm 1.96 \times \sqrt{D_{22}} \\
\lim C_{\text {grid }}(b) & =C_{\text {grid }}(b) \pm 1.96 \times \sqrt{D_{33}}
\end{aligned}
$$

where $D_{11}, D_{22}$, and $D_{33}$ are the diagonal elements in the estimated between-haul variation matrix for the selected model, see Fryer (1991) for details.

The size-selection parameters $L 50_{\text {grid }}, S R_{\text {grid }}$, and $C_{\text {grid }}$ were predicted for grid-bar spacing between $30 \mathrm{~mm}$ and $70 \mathrm{~mm}$ by using model 4 . Based on equation (3), we calculated the mean available selection parameters $L 50_{\mathrm{a}}$ and $S R_{\mathrm{a}}$ for different bar spacing from the corresponding values of $L 50_{\text {grid }}$, $S R_{\text {grid }}$, and $C_{\text {grid. }}$.

The analysis described in this section was conducted using the analysis tool SELNET described in the previous section. Further information on how to apply SELNET for the type analysis described in this section can be found in Wienbeck et al. (2011).

\subsection{Modelling the dual selection in the system: a Sort-V grid and a subsequent size-selective codend}

The design in Figure $2 \mathrm{~b}$ was applied to collect the data to assess the size selectivity of the Sort- $\mathrm{V}$ grid $(55 \mathrm{~mm})$ combined with the diamond mesh codend (135 and $140 \mathrm{~mm}$, respectively). During the trials with the Sort-V grid, every fish was counted in all three compartments. Thus, for each individual haul separately we had information on the number of redfish $n_{\mathrm{gcl}}$ contained in the grid cover GC, the number $n_{\mathrm{cl}}$ contained in the codend $\mathrm{C}$, and the number $n_{\mathrm{ccl}}$ contained in the codend cover $\mathrm{CC}$. An initial inspection of the data collected with setup 1 and setup 2 showed that the number of redfish collected in the individual hauls was too sparse to enable haul by haul analysis. Therefore, we employed another approach to estimate the size selection in the combined systems. Our approach involved pooling the data and estimating the average size selection for each system separately. Bootstrapping was used to estimate the confidence limits for the average selection parameters. This approach avoids underestimation of the confidence limits of the average selection parameters by accounting for both within- and between-haul variation in the selection processes.

We assumed that the available size selection for the Sort-V grid can be modelled by the clogit function (Eq. (2)) for the average data. This takes into account that some fish may not contact the Sort-V grid. For the size selection in the subsequent codends (either the $135 \mathrm{~mm}$ or the $140 \mathrm{~mm}$ codend), we assumed that it was sufficient to use a standard logit function to model the retention probability.

Based on the above procedure, the negative log likelihood function was minimized with respect to the parameters $v$ and $w$ to estimate the dual selection (averaged over hauls) in the system consisting of the Sort-V grid and a size-selective codend:

$$
\begin{aligned}
-\sum_{l} \sum_{i}^{\text {hauls }}\left\{n_{\text {gcil }} \times \ln \left(e_{\text {grid }}(l, v)\right.\right. & +n_{\text {ccil }} \times \ln \left(e_{\text {codend }}(l, v, w)\right) \\
& \left.+n_{\text {cil }} \times \ln \left(r_{\text {combined }}(l, v, w)\right)\right\} .
\end{aligned}
$$

Here, $i$ denotes summation over hauls in which the specific codend was applied together with the Sort-V grid; $l$ denotes summation over length classes; $e_{\text {grid }}(l, v), e_{\text {codend }}(l, v, w)$, and $r_{\text {combined }}(l, v, w)$, respectively, denote the length-dependent probabilities for a fish escaping through the grid, escaping through the codend, or being retained in the codend given that it enters the combined selective system. $e_{\text {grid }}(l, v)$, $e_{\text {codend }}(l, v, w)$, and $r_{\text {combined }}(l, v, w)$ are modelled by:

$$
\begin{aligned}
e_{\text {grid }}(l, v)= & 1.0-\operatorname{clogit}\left(l, L 50_{\text {grid }}, S R_{\text {grid }}, C_{\text {grid }}\right) \\
e_{\text {codend }}(l, v, w)= & \left(1.0-\operatorname{logit}\left(l, L 50_{\text {codend }}, S R_{\text {codend }}\right)\right) \\
& \times \operatorname{clogit}\left(l, L 50_{\text {grid }}, S R_{\text {grid }}, C_{\text {grid }}\right) \\
r_{\text {combined }}(l, v, w)= & \operatorname{clogit}\left(l, L 50_{\text {grid }}, S R_{\text {grid }}, C_{\text {grid }}\right) \\
& \times \operatorname{logit}\left(l, L 50_{\text {codend }}, S R_{\text {codend }}\right) .
\end{aligned}
$$

Thus, the parameters being estimated are $L 50_{\text {grid }}, S R_{\text {grid }}, C_{\text {grid }}$, $L 50_{\text {codend }}$, and $S R_{\text {codend }}$. We were unable to derive analytical expressions for the combined selection parameters $L 50_{\text {combined }}$ and $S R_{\text {combined }}$ based on $r_{\text {combined }}$, and therefore we used a numerical method identical to the one applied by Sistiaga et al. (2010) to estimate these parameters. We used the definition for $L 50$ as the length at which $r(l)=0.5(50 \%$ likelihood for being retained). We used the values for $C_{\text {grid }}, L 50_{\text {grid }}, S R_{\text {grid }}$, $L 50_{\text {codend }}$, and $S R_{\text {codend }}$ estimated from (Eq. (7)) and numerically solved $r(l)=0.5$. The length $l$ fulfilling this condition then was set equal to $L 50_{\text {combined }}$. Using $S R_{\text {combined }}=$ $L 75_{\text {combined }}-L 25_{\text {combined }}$, we estimated $S R_{\text {combined }}$ using the same approach as for $L 50_{\text {combined }}$.

Besides quantifying the observed codend escapement probability, as described by $e_{\text {codend }}(l, v, w)$, when the codend is installed after a grid, it is also of interest to estimate codend escapement probability $e_{\text {codend_con }}(l, w)$ for the fish actually entering the codend (codend escapement conditional on having been retained by the grid).

Escapement probability $e_{\text {codend_con }}(l, w)$ is relevant in situations where the grid escapement fails.

$$
e_{\text {codend_con }}(l, w)=1-\operatorname{logit}\left(l, L 50_{\text {codend }}, S R_{\text {codend }}\right)
$$


The estimation of the $95 \%$ confidence limits for the lengthdependent average grid escapement, codend escapement, and combined retention likelihood followed the procedure described in Sistiaga et al. (2010), Herrmann et al. (2012) and Eigaard et al. (2011), based on the applied bootstrapping technique.

\subsection{Predicting grid size selection for redfish using the FISHSELECT method}

FISHSELECT is a fish morphology data- and simulationbased methodology that can be applied to investigate the basic size-selective properties of meshes of different shape and size for individual fish species (Herrmann et al. 2009). It has been applied to study codend size selection for species such as cod (Herrmann et al. 2009; Sistiaga et al. 2011), haddock (Krag et al. 2011; Sistiaga et al. 2011), Nephrops norvegicus (Frandsen et al. 2010), and redfish (Herrmann et al. 2012). The FISHSELECT models for redfish established by Herrmann et al. (2012) were applied to predict the selective potential of grids with different bar spacing. This was done with the so called "penetration model" for redfish and a virtual redfish population from Herrmann et al. (2012), using a new "mesh list file" consisting of "rectangular meshes". These "rectangular meshes" emulate the openings between the bars of grids with different bar spacing. The aim is to simulate the potential size selection for each of the "meshes" in the mesh list file (see Herrmann et al. 2009; 2012 for further details on the procedure and for FISHSELECT terms). Using this approach, we simulated the size-selective potential for redfish for grids with bar spacing of 30 to $70 \mathrm{~mm}$ in steps of $5 \mathrm{~mm}$.

When using FISHSELECT to predict size selection through codend meshes, it is assumed that a fish has multiple chances to escape, especially when it swims just ahead of the catch bulk in the codend. Therefore, the traditional FISHSELECT analysis has assumed that fish seek escapement through the meshes with optimal orientation. However, this assumption is not necessarily valid when estimating escapement through a grid positioned ahead of the codend. In grid + codend systems, it might be that some of the redfish will have few opportunities to contact the grid due to high fish densities in the grid zone or short time in the grid zone. Thus, some fish might have limited number of opportunities to escape through the grid and limited chances to orientate themselves optimally for doing so. If some fish are sub-optimally orientated at the point when they come into contact with the grid, the standard FISHSELECT approach would overestimate the size selection of the grid, as it assumes optimal orientation of all fish. Redfish are flattest along the plane symmetry that extends through the midpoints between the pectoral fins and the dorsal fin. Hence, a fish's chances of escapement are maximized when it orients its plane of symmetry parallel to the bars of the grid (Fig. 3). The angle between this plane and the grid bars will be referred to from here on as "the angle of attack" or "orientation angle" $(\varnothing)$.

To investigate the potential effect of sub-optimal $\varnothing$, we applied a recent development in the FISHSELECT software package that enables simulation of the size selectivity for different fixed $\varnothing$ values. We used this facility to predict the size

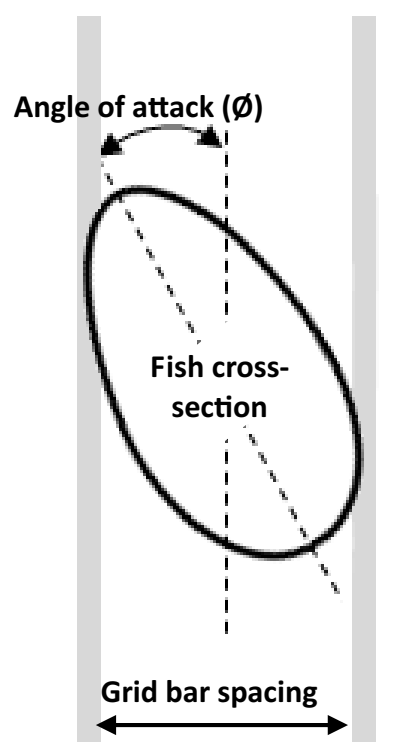

Fig. 3. Illustration of a situation with a redfish contacting a grid space with a grid attack angle $\varnothing$ different from the optimal angle (0 degree), after Herrmann et al. (2012).

selection for $\varnothing$ between 0 and 90 degrees, in steps of 5 degrees for grids with bar spacing between 30 and $70 \mathrm{~mm}$ in steps of $5 \mathrm{~mm}$.

If most redfish which contacted the grid did so with optimal $\varnothing$, then we would expect that the experiment-based values for $L 50_{\text {grid }}$ for the Sort-X and for the Sort-V would be close to those obtained with FISHSELECT with $\varnothing=0$ for the same grid-bar spacing. For the Sort-X grid we could make this comparison for a range of bar spacing by using the results based on the approach described in Section 2.3. For the Sort-V, we could only make this comparison for the 55-mm bar spacing tested during the Jan Mayen cruise (Sect. 2.1.2). If the experimentbased $L 50_{\text {grid }}$ values are significantly smaller than the values obtained with FISHSELECT (for $\varnothing=0$ ) this might be due to that not all of the redfish contacting the grid did it with an optimal $\varnothing$. To investigate if a mixture of different angles of attack can explain the experimental results obtained from the sea trials, we tested if it was possible to achieve the $L 50$ values obtained from the sea trial data by combining FISHSELECT size-selection data for different $\varnothing$ values. If a given mixture of $\varnothing$ values (from $0^{\circ}$ to $90^{\circ}$ in steps by $5^{\circ}$ ) over a range of different bar spacing closely reproduces the sea trial based results, the combination of different attack angles can be identified as a mechanism that may contribute to explain size selection of redfish in grids. Accordingly, we combined simulated FISHSELECT size-selection data for different $\varnothing$ values and investigated if it was possible to find a mixture that led to simulated size-selection data with L50 values that resemble the experiment-based results. The mixture of $\varnothing$ values was automatically selected using an algorithm in the FISHSELECT software package. This algorithm, which is based on the same principles as the one described in Frandsen et al. (2010), compares the entire simulated selection curve (from 5\% retention probability to $95 \%$ retention probability in steps of $5 \%$ ) with the one estimated based on the experimental fishing data to select the mixture of $\varnothing$ values that makes the curves as 
Table 1. Results for individual hauls collected using the Sort-X grid. Results are based on the Clogit model. Values in brackets are 95\% confidence limits.

\begin{tabular}{|c|c|c|c|c|c|c|c|c|c|c|c|}
\hline Haul & $\begin{array}{c}\text { Grid } \\
(\mathrm{mm})\end{array}$ & $\begin{array}{l}L 50_{\mathrm{a}} \\
(\mathrm{cm})\end{array}$ & $\begin{array}{l}S R_{\mathrm{a}} \\
(\mathrm{cm})\end{array}$ & $\begin{array}{l}L 50_{\text {grid }} \\
(\mathrm{cm})\end{array}$ & $\begin{array}{c}S R_{\text {grid }} \\
(\mathrm{cm})\end{array}$ & $C_{\text {grid }}$ & $p$-Value & Dev & $d f$ & $\begin{array}{c}\text { AIC } \\
\text { Clogit }\end{array}$ & $\begin{array}{c}\text { AIC } \\
\text { Logit }\end{array}$ \\
\hline 1 & 40 & $28.8(27.7-29.6)$ & $5.5(4.7-6.5)$ & $28.9(27.7-29.6)$ & $5.5(4.7-6.5)$ & 1 & 0.986 & 25.24 & 43 & 392 & 390 \\
\hline 2 & 40 & $28.2(26.0-29.6)$ & $7.3(*-11.0)$ & $29.3(26.8-30.8)$ & $4.9(3.9-6.5)$ & $0.82(0.61-1)$ & 0.994 & 21.85 & 41 & 358 & 362 \\
\hline 3 & 45 & $26.9(23.9-28.1)$ & $*$ & $29.6(26.3-32.9)$ & $7.9(5.3-$ & $0.73(0.5$ & 0.685 & 9 & 39 & 744 & 747 \\
\hline 4 & 45 & $27.1(25.8-28.3)$ & $8.4(6.9-9.8)$ & $27.1(25.8-28.3)$ & $8.4(6.9-9.8)$ & 1 & 0.721 & & 40 & 454 & 452 \\
\hline 5 & 45 & $23.0(19.4-2$ & $12.4(*-20.4)$ & $24.6(21.4$ & $9.2(7.2-$ & $0.84(0.6$ & 34 & 46 & 40 & 381 & 380 \\
\hline 6 & 50 & $36.8(34.7-39.0)$ & $13.8(*-16.9)$ & $38.8(35.0-41.6)$ & $7.1(3.9-11.0)$ & $0.77(0.61-1)$ & 0.986 & 28.32 & 47 & 325 & 331 \\
\hline 7 & 50 & $30.8(*-33.2)$ & $*$ & $38.5(34.7-40.3)$ & $7.2(4.7-11.6)$ & $0.55(0.46-0.78)$ & 0.204 & 36.14 & 30 & 1196 & 1201 \\
\hline 8 & 50 & $34.4(33.4-35.3)$ & $12.6(*-19.4)$ & $36.1(33.7-37.8)$ & $8.8(6.9-11.4)$ & $0.82(0.70-1)$ & 0.882 & 24 & 44 & 1471 & 1474 \\
\hline 9 & 50 & $38.1(37.4-38.8)$ & $9.5(8.1-11.2)$ & $39.0(37.7-40.1)$ & $7.9(6.0-10.1)$ & $8(0.80-1)$ & 0.925 & 78 & 35 & 1239 & 1244 \\
\hline 10 & 50 & $42.7(42.1-4$ & $9.3(7.2-11.5)$ & $43.2(42.3-4$ & $8.7(6.2-$ & & 91 & & 39 & 1165 & 1167 \\
\hline 11 & 50 & $35.7(34.7-36.4)$ & $9.1(7.9-11.4)$ & $36.8(34.9-3$ & $7.1(6.1$ & 1) & 0.711 & 49 & 42 & 1064 & 1073 \\
\hline 12 & 50 & $24.7(14.5-2$ & $20.3(*-23.6)$ & $27.2(23.1-$ & $8.4(7.0$ & $0.76(0$. & 0.461 & & 34 & 1122 & 1121 \\
\hline 13 & 50 & $34.8(32.9-36.2)$ & $11.2(*-18.9)$ & $36.2(34.4-38.8)$ & $8.4(6.0-10.6)$ & $0.84(0.65-0.94)$ & 0.186 & 46.69 & 39 & 570 & 572 \\
\hline 14 & 50 & $33.8(32.9-34.8)$ & $12.3(10.9-13.8)$ & $34.4(33.1-35.8)$ & $11.5(9.7-13.4)$ & $0.95(0.90-1)$ & 0.405 & 43.56 & 42 & 1071 & 1071 \\
\hline 15 & 50 & $33.5(32.0-34.6)$ & $*$ & $37.5(35.5-38.6)$ & $7.2(5.7-9.9)$ & $0.65(0.58-0.76)$ & 0.273 & 41.72 & 37 & 1396 & 1424 \\
\hline 16 & 50 & $27.9(26.3-29.2)$ & $14.2(*-24.2)$ & $29.7(27.0-32.6)$ & $10.8(8.2-13.6)$ & $0.85(0.64-1)$ & 0.125 & 42.46 & 33 & 1211 & 1210 \\
\hline 17 & 50 & $31.9(31.1-32.7)$ & $13.8(12.1-15.7)$ & $31.9(31.1-32.7)$ & $13.8(12.1-15.7)$ & 1 & 0.397 & 37.58 & 36 & 1451 & 1449 \\
\hline
\end{tabular}

*: not defined, df: degrees of freedom.

Table 2. Results of the Fryer model applied to the Sort-X grid data

\begin{tabular}{ccccccc}
\hline & Parameter & Multiplier & Value & SE & $95 \%$ CI & $p$-value \\
\hline$L 50_{\text {grid }}$ & $p_{11}$ & $b$ & 0.695 & 0.022 & $0.652-0.739$ & $<0.0001$ \\
$S R_{\text {grid }}$ & $p_{12}$ & $b$ & 0.176 & 0.010 & $0.156-0.197$ & $<0.0001$ \\
$C_{\text {grid }}$ & $p_{03}$ & none & 0.850 & 0.034 & $0.781-0.920$ & $<0.0001$ \\
\hline \multicolumn{7}{c}{ Between-haul variation } \\
\hline$D_{11}$ & 17.564 & $D_{12}$ & -3.573 & $D_{13}$ & -0.054 \\
$D_{22}$ & 2.901 & $D_{23}$ & 0.092 & $D_{33}$ & 0.015 \\
\hline
\end{tabular}

similar as possible. The mixture of $\emptyset$ s was estimated based on results for grid-bar spacing $55 \mathrm{~mm}$.

\section{Results}

\subsection{Experimental results for the Sort-X grid}

We conducted 17 valid hauls with the Sort-X grid on the cruise carried out aboard the M/V Prestfjord. The haul data were analysed individually according to the procedure outlined in Section 2.2.

The clogit model with a length-independent $C_{\text {grid }}$ revealed that $p>0.05$ for all hauls, i.e., the deviations observed between the data and the clogit model could well be a coincidence (Table 1). Thus, the experimental data was sufficiently well modelled based on a model with a length-independent value for $C_{\text {grid }}$. We also calculated the AIC values for the $c l o g i t$ model and the logit model (Table 1). For 11 out of the 17 hauls, the AIC value estimated for the clogit model was lower than for the logit model. Further the sum of the AIC values for the clogit model was found to be 57 smaller than for the logit model. Thus, the clogit model is preferable to the standard logit model for describing size selection for the Sort-X grid. This result demonstrates the relevance of applying a model like clogit, which explicitly considers the grid-contact likelihood. This premise is further supported by the estimated values for the grid-contact likelihood $\left(C_{\text {grid }}\right)$ for individual hauls. For several hauls, $C_{\text {grid }}$ was considerably below 1.0 (Table 1 ). Thus, many of the redfish entering the Sort-X grid section do not contact any of the two grids (Fig. 1). For three hauls, the estimated $C_{\text {grid }}$ value was significantly lower than 1.00. Further for three hauls, $C_{\text {grid }}$ was less than 0.75, which makes $S R_{a}$ undefined. Due to the values of $C_{\text {grid }}$, the estimated $L 50_{\mathrm{a}}$ values are at least $1 \mathrm{~cm}$ below the corresponding $L 50_{\text {grid }}$ 's in more than half of the hauls (Table 1).

To estimate the effect of grid bar spacing on the size selection of the Sort-X grid, the results from the 17 individual hauls conducted (Table 1) were analysed together following the procedure described in Section 2.3. Table 2 summarizes the results from the resulting model (more information on how to interpret this type of information can be found in Fryer 1991).

Both mean $L 50_{\text {grid }}$ and mean $S R_{\text {grid }}$ are predicted to increase with increase in grid-bar spacing since the slope parameters $p_{11}$ and $p_{12}$ are both significantly bigger than 0 (Table 2). The analysis showed that both intercept parameters $p_{01}$ and $p_{02}$ 
were non-significant and therefore not present in the selected model 9. According to the model, mean $C_{\text {grid }}$ does not depend on the slope parameter $p_{13}$, but it has a significant intercept term. Thus, model 4 can be reduced to:

$$
\begin{aligned}
L 50_{\text {grid }}(b) & =p_{11} \times b \\
S R_{\text {grid }}(b) & =p_{12} \times b \\
C_{\text {grid }}(b) & =p_{02} .
\end{aligned}
$$

The absence of intercept terms in model 9 for both $L 50_{\text {grid }}$ and $S R_{\text {grid }}$ makes sense from a structural point of view, as it is expected that the size of a fish that would be able to escape through the grid would progress towards 0 for bar spacing progressing towards 0 . This should also be the case for $L 50_{\text {grid }}$ and $S R_{\text {grid. }}$. Model 9 complies with this structural expectation and it makes more permissible to use it for predictions outside the range of the bar spacing, after Fryer and Sheppard (1996). Mean $C_{\text {grid }}$ is estimated to be approximately 0.85 , i.e. $85 \%$ of redfish individuals in a typical haul will come into contact with the Sort-X grid and thereby have a length-dependent chance to escape through it. The confidence limits for the mean value of $C_{\text {grid }}$ show that the upper limit $(\approx 0.92)$ is considerably below 1 , which demonstrates the importance of explicitly considering grid-contact likelihood when modelling size selection of redfish in Sort-X systems.

Figure 4 plots the selection parameters for individual haul results (diamonds) against the predicted mean value for different bar spacing grids (solid line) and the confidence limits for the predicted between-haul variation (stippled line). No individual haul contradicts the model as there is overlap in confidence limits between the results from single hauls and the model predictions for all three parameters (Fig. 4). $L 50_{\text {grid }}$ is predicted to increase by $7.0 \mathrm{~cm}$ (CI: $6.5-7.4 \mathrm{~cm})$ and $S R_{\text {grid }}$ is predicted to increase by $1.8 \mathrm{~cm}(\mathrm{CI}: 1.6-2.0 \mathrm{~cm})$ for an increase in gridbar spacing of $1 \mathrm{~cm}$ (Table 2). For the current legal bar spacing of $5.5 \mathrm{~cm}$, our model predicts a mean $L 50_{\text {grid }}$ of $38.2 \mathrm{~cm}$ (CI: $35.8-40.7 \mathrm{~cm}$ ), while mean $S R_{\text {grid }}$ is predicted to be $9.7 \mathrm{~cm}$ (CI: $6.4-10.8 \mathrm{~cm}$ ). With $C_{\text {grid }} \approx 0.85$, the corresponding parameters $L 50_{\mathrm{a}}$ and $S R_{\mathrm{a}}$ are $36.7 \mathrm{~cm}$ (CI: 34.2-39.1 cm) and $12.7 \mathrm{~cm}(\mathrm{CI}: 10.5-15.0 \mathrm{~cm})$, respectively.

\subsection{Experimental results for the Sort- $V$ grid combined with a selective codend}

Analysis of the size-selection processes in the combined selection system consisting of a 55-mm bar spacing Sort-V grid, followed by a size-selective diamond mesh codend with mesh sizes of $135 \mathrm{~mm}$ (setup 1) or $140 \mathrm{~mm}$ (setup 2) provided the results shown in Table 3 and Figure 5 (methods described in Sect. 2.4).

The grid accounts for most of the redfish escapement (Fig. 5, panels a-b vs. panels c-d). However, a small portion of the fish entering the combined system is estimated to escape through the codend meshes (panels $\mathrm{c}$ and $\mathrm{d}$ ). The low escapement probability of the codends is mostly due to that they are placed after the grids, and not due to lack of escapement potential (Fig. 5: panels e-f vs. panels c-d). The fit statistics for the model (Eqs. (6) and (7)) are acceptable $(p>0.05)$, and
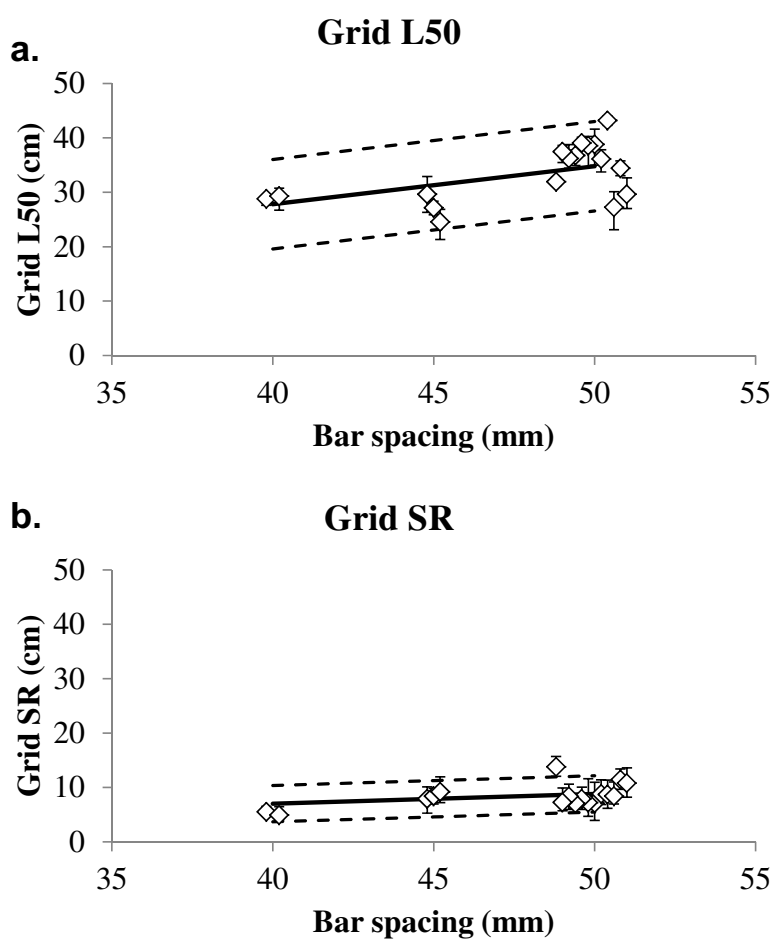

c.

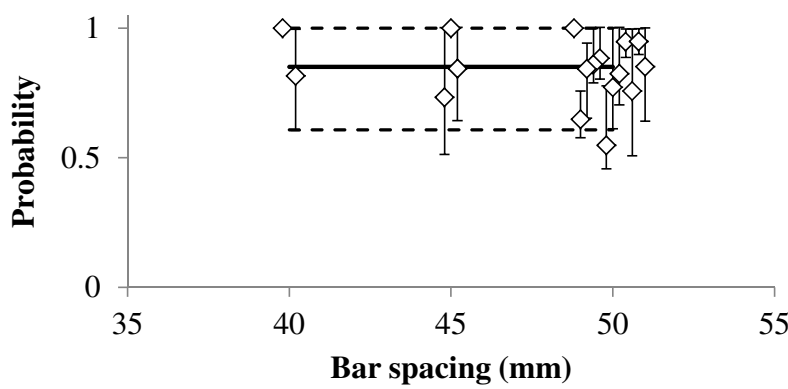

Fig. 4. Results for individual hauls using Sort-X grids (diamonds) plotted on the result predicted from applying the model 9 (black line). The stippled lines are the predicted 95\% confidence bands for the between-haul variation. (a) Grid $L 50$, (b) grid $S R$, and (c) grid contact probability.

the model deviances do not exceed the degrees of freedom. Therefore, we are confident in applying the model to the two datasets.

The estimated $C_{\text {grid }}$ values (Table 3$)$ were high $(1.00$ and 0.95 , respectively) but with a lower limit CI $(0.46$ and 0.52). Because of the width of the confidence intervals, we cannot draw any conclusion regarding $C_{\text {grid }}$ for Sort-V grid systems based on these data.

\subsection{FISHSELECT prediction and comparison with experimental results}

Following the procedure described in Section 2.5, The morphological limits for grid size selection were estimated for grids with different bar spacing (30-70 mm) and for different 

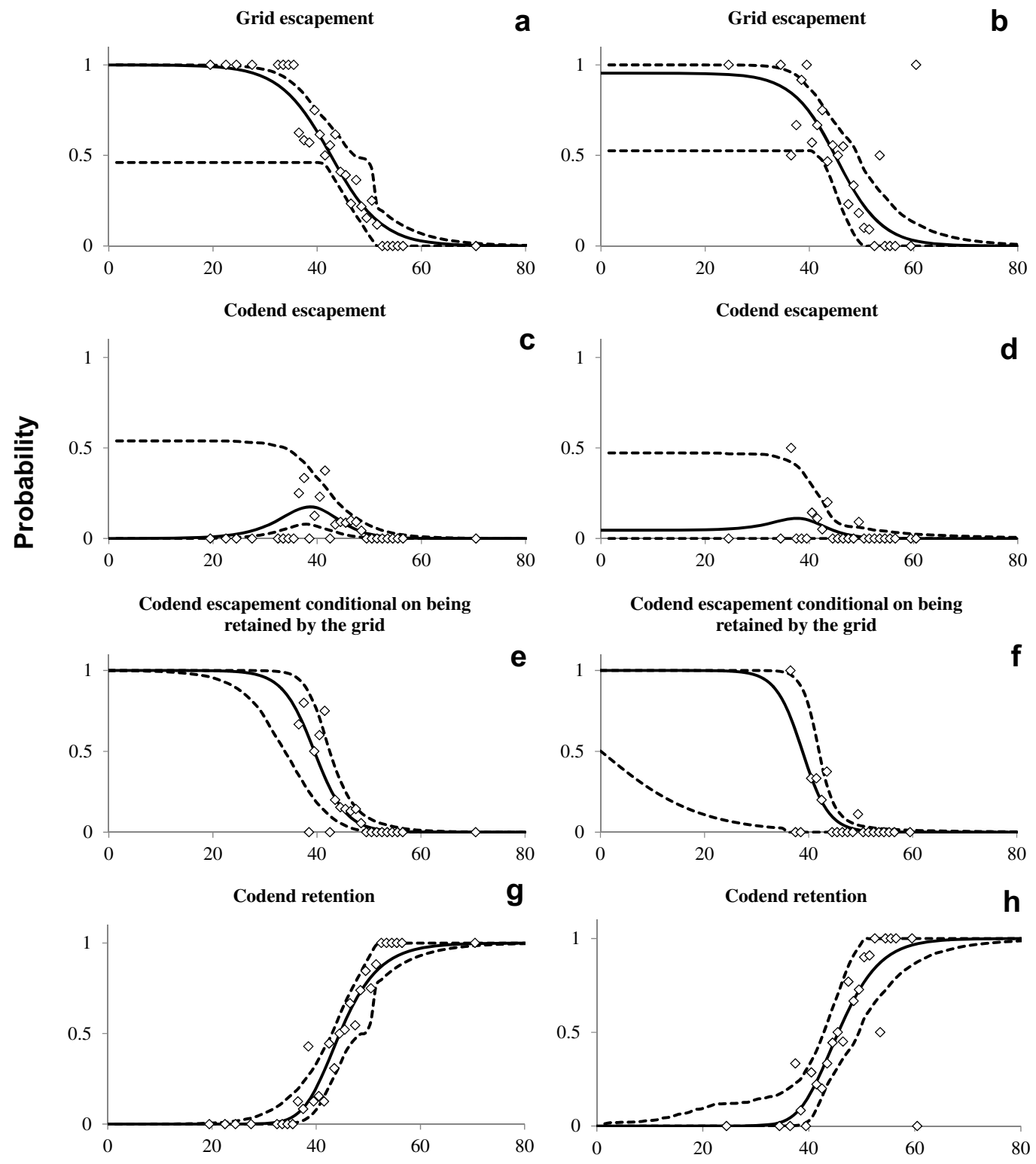

Fish length (cm)

Fig. 5. Escapement pattern from trials conducted with the Sort-V grid followed by a size selective codend (135-mm codend for panels a, c, e, and g; 140-mm codend for panels b, d, f, and h). (a)-(b) Grid escapement probability. (c)-(d) Codend escapement probability. (e)-(f) Codend escapement probability conditional on being retained by the grid. (g)-(h) Probability of being retained in the codend. Experimental results are shown (diamonds) vs. results based on fitting the model 6-8 (black lines) to the experimental data. The stippled lines are the predicted 95\% confidence bands for the fitted model.

fixed $\varnothing$ values (0-90 degrees). The size-selective potential for the grid decreases with increasing $\varnothing$ (Fig. 6).

We plotted FISHSELECT grid 250 value predictions for different grid-bar spacing and two different scenarios (Fig. 7): I) where all fish contacting the grid are assumed to do it with an optimal angle of attack ( $\varnothing=0$; grey curve); II) where fish are assumed to contact the grid with a mixture of different $\varnothing$ values (black curve). The black curve was found to be able to replicate the model predictions for the Sort-X grid (model 9). The same mixture of $\varnothing$ values was applied for all bar spacings. The diamond marks in Figure 7 represent the mean values predicted for $L 50_{\text {grid }}$ by model 9 for the Sort-X grid while the squares represent the experimental $L 50_{\text {grid }}$ values for the Sort-V grid (setups 1 and 2). The error bars are the $95 \%$ confidence limits for these estimates. Figure $7 \mathrm{~b}$ shows the mixture of $\varnothing$ applied for scenario I (grey bars) and scenario II (black bars). For scenario II, more than $50 \%$ of the redfish individuals are assumed to attack the grid with an angle that does not differ more than 5 degrees from the optimal.

For the Sort-X grid, the experimentally obtained $L 50_{\text {grid }}$ is significantly lower than the size-selective potential of the grid based on the morphology of redfish (Fig. 7: diamond 
Table 3. Pooled results for the cruise with the 55-mm Sort-V grid + selective codends (135 and $140 \mathrm{~mm}$ ).Values in brackets are $95 \%$ confidence limits.

\begin{tabular}{lcc}
\hline & $\begin{array}{c}\text { Grid }+135-\mathrm{mm} \\
\text { codend }\end{array}$ & $\begin{array}{c}\text { Grid }+140-\mathrm{mm} \\
\text { codend }\end{array}$ \\
\hline No. hauls & 11 & 6 \\
No. in grid cover & 111 & 102 \\
No. in codend cover & 24 & 10 \\
No. in codend & 158 & 99 \\
$L 50_{\text {combined }}(\mathrm{cm})$ & $44.5(42.0-48.9)$ & $45.6(42.8-49.4)$ \\
$S R_{\text {combined }}(\mathrm{cm})$ & $8.1(5.5-11.1)$ & $8.4(4.4-14.3)$ \\
$C_{\text {grid }}$ & $1(0.46-1)$ & $0.95(0.52-1)$ \\
$L 50_{\text {grid }}(\mathrm{cm})$ & $42.6(40.6-50.6)$ & $45.4(42.3-50.3)$ \\
$S R_{\text {grid }}(\mathrm{cm})$ & $10.8(0.1-14.6)$ & $9.5(0.1-16.0)$ \\
$L 50_{\text {codend }}(\mathrm{cm})$ & $39.5(34.2-42.7)$ & $38.8(0.1-42.6)$ \\
$S R_{\text {codend }}(\mathrm{cm})$ & $6.7(3.8-11.5)$ & $5.6(0.1-33.1)$ \\
$p$-value & 0.99 & 0.61 \\
Degrees of freedom & 55 & 45 \\
Deviance & 32.98 & 41.70 \\
\hline
\end{tabular}

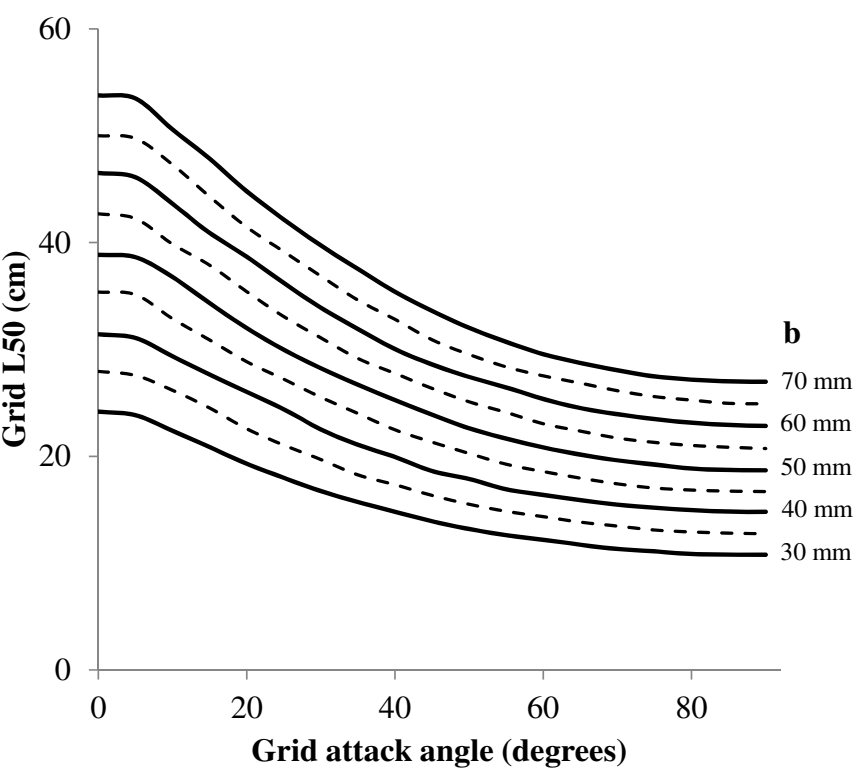

Fig. 6. FISHSELECT-predicted grid $L 50$ values for different grid-bar spacing (b values) and different grid attack angle values for redfish. Stippled curves are for b values at $35,45,55$ and $65 \mathrm{~mm}$ respectively.

marks vs. grey curve). The results seem to have a fairly constant offset compared to the FISHSELECT morphological limit (all fish with $\varnothing=0$ ). A linear regression on the FISHSELECT $\varnothing=0$ supports the interpretation of a constant relationship and shows an increase in $L 50$ of $7.3 \mathrm{~cm}$ for each $\mathrm{cm}$ increase in grid-bar spacing. This slope value is within the confidence limits $(6.5-7.4 \mathrm{~cm})$ obtained based on the experimental results (model 9, Table 2). Thus, the morphologically-based predictions of an increase in L50 values for any given increase in grid-bar spacing seem to agree well with the corresponding experimentally-based predictions. Further, differences between the FISHSELECT predictions and the experiment-based results could be that not all redfish
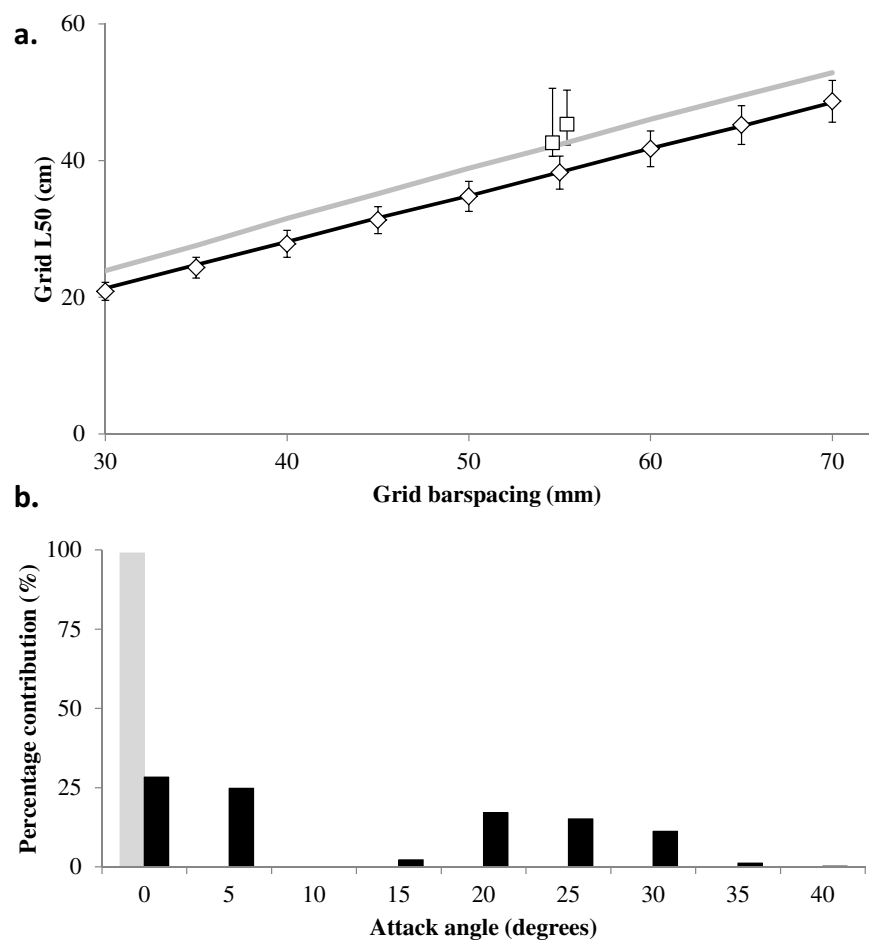

Fig. 7. (a) FISHSELECT-predicted grid $L 50$ for different grid-bar spacing for two different scenarios: (I) where all fish contacting the grid are assumed to have an optimal angle of attack $(\varnothing=0$; grey curve); (II) where the fish contacting the grid are assumed to have a mixture of different attack angles (black curve). The same mixture of attack angles were applied for all bar spacing. The diamonds represent the mean values predicted for $L 50_{\text {grid }}$ by the model 9 , for the Sort-X grid while the squares represent the experimental $L 50_{\text {grid }}$ values for the Sort-V grid (setup 1 and 2). The error bars are the $95 \%$ confidence limits for these predictions. (b) Mixture of attack angles applied for scenario I (grey bar) and scenario II (black bars).

that attempt to escape through the grid make their attempt with an optimal angle of attack (diamonds vs. black curve).

In contrast to the results for the Sort- $\mathrm{X}$ grids, the Sort- $\mathrm{V}$ results overlap with the morphological limits for $L 50$ (grey curve in Fig. 7a). This result could indicate that redfish may manage to orientate themselves more optimally towards the Sort-V grid than towards the Sort- $X$ grid. However, we cannot rule out other explanations related to differences between the two cruises (such as differences in fish densities).

\section{Discussion}

Using experimental data from fishing and morphological data collected on redfish, we investigated the size-selective properties of the Sort- $\mathrm{X}$ and the Sort-V grids. For the Sort-X system, the analysis showed that not all redfish entering the grid zone come into contact with the grid; we estimated that $\sim 85 \%$ do (Table 2). The fact that $15 \%$ of the fish do not contact the Sort-X grid demonstrates the importance of using this grid in combination with a subsequent size-selective codend. The codend gives the undersized redfish that did not contact the grid an additional chance to escape through the meshes of the codend. From a management point of view, it is 
important that the codends used in combination with the grids have size-selective properties that are similar to those of the grid. Our results indicate that $C_{\text {grid }}$ could be higher for the Sort$\mathrm{V}$ system compared to the Sort-X. A reason for that could be the presence of the lifting panel in the Sort-V system, which guides the fish towards the grid. However, our results are only indicative due to very broad confidence limits for $C_{\text {grid }}$ for the Sort- $V$ data. A further study on this subject could focus on investigating the effect on $C_{\text {grid }}$ by the lifting panel in the Sort-V system. In future experimental sea trials, some hauls could be conducted with the lifting panel installed and others without it. Then, by using the models presented in this paper, with the presence of the lifting panel as fixed effect in an analysis based on the method by Fryer (1991), the effect of the lifting panel on $C_{\text {grid }}$ could be quantified. In general, the models presented in this paper could be applied to study the size selection of other species in grid-based selection systems. The results from such work may help optimizing future grid-based selection systems.

Factors like densities of fish in the grid zone and water temperature could potentially influence both $C_{\text {grid }}$ and the ability of fish to orientate themselves optimally for grid escapement. In this study, we have not been able to consider such factors, and any extrapolation of our results to situations where these factors are considerably different from the conditions of the reported fishing experiments may therefore not be fully valid. Since redfish individuals of different sizes are expected to differ in terms of swimming abilities, speed, reaction times and other behavioural factors which could affect grid contact probability, it seems likely that the value for $\mathrm{C}_{\text {grid }}$ would be length dependent. However, since the assumption of a lengthindependent $C_{\text {grid }}$ led to a model which was able to describe the experimental data included in this study sufficiently well, we did not find any indication of a need to consider length dependent effects for $C_{\text {grid }}$.

For the redfish contacting the grids of the Sort-X system, we found that the increase in $L 50$ values would be around $7 \mathrm{~cm}$ for each $\mathrm{cm}$ increase in grid-bar spacing. This is what would be expected based on our study of the morphology of redfish by means of the FISHSELECT method. However, the experiment-based results are significantly below the expected values based on the morphology of redfish. Computer simulations demonstrated that this difference may be explained if some of the redfish contacting the grid are not able to do this with an optimal angle of attack. Assuming such a mechanism, we obtained simulated results over a range of grid-bar spacing that closely resembled the experiment-based results. However, this explanation is speculative and lacks support from, for example, underwater recordings. Underwater observations (by R.B. Larsen, the third author of this study) on behaviour of other species in the Sort-X grid system have shown that fish often have difficulties in orientating themselves optimally for escapement through the second and horizontal grid. This is a consequence of the narrow space between this grid and the lower panel in the grid section (down to about $20 \mathrm{~cm}$ during fishing; Fig. 1). The distribution of angles of attack (Fig. 7b) seem to comprise two separate distributions, for the two different grids in the Sort-X system (Fig. 1b). Thus, the first distribution (attack angles between $0^{\circ}$ and $5^{\circ}$ ) for approximately $50 \%$ of the fish contacting one of the grids could be the contact with the first grid. In turn, the remaining attack angles (from $15^{\circ}$ to $40^{\circ}$ ) could represent the contact with the second, less well positioned, grid. Our results illustrate how models based on fish morphology may contribute to the understanding of size selection of redfish in sorting grids.

We raised the question of how much of the total release of redfish in the combined grid and codend system happens through the grid. Thus, for the Sort- $\mathrm{V}$ grids, most of the redfish escape through the grid (Fig. 5), and this is mainly due to the fact that the grid is placed ahead of the codend, and not due to lack of selective potential in the codend.

Acknowledgements. We thank the crew members and research assistants who participated in the three cruises providing data for this study. Our thanks also go to two anonymous reviewers who helped to improve the paper considerably.

\section{References}

Akaike H., 1974, A new look at the statistical model identification. IEEE Trans. Auto. Control 19, 716-722.

Angell S., 1999, Development of a flexible selection system for fish trawls. Master thesis. Norwegian College of Fishery Science, University of Troms $\varnothing$.

Chernick M.R., 2007, Bootstrap methods: A guide for practitioners and researchers, second edition. Wiley Series in Probability and Statistics, Wiley, New York.

Collins L.M., Lanza S. T., 2010, Latent class and latent transition analysis: with applications in the social, behavioral, and health sciences. New York, John Wiley \& Sons.

Efron B., 1982, The jackknife, the bootstrap and other resampling plans. SIAM Monograph No 38, CBSM-NSF.

Eigaard O., Herrmann B., Nielsen J. R., 2011, Influence of grid orientation and time of day on grid sorting in a small-meshed trawl fishery for Norway pout (Trisopterus esmarkii). Aquat. Living Resour. 25, 15-26.

Frandsen R.P., Herrmann B., Madsen N., 2010. A simulation-based attempt to quantify the morphological component of size selection of Nephrops norvegicus in trawl codends. Fish. Res. 101, 156-167.

Fryer R.J., 1991, A model of between-haul variation in selectivity. ICES J. Mar. Sci. 48, 281-290.

Fryer R.B., Shephard J.G., 1996, Models of codend size selection. J. Northw. Atl. Fish. Sci. 19, 51-58.

Herrmann B., Krag L.A., Frandsen R.P., Madsen N., Lundgren B., Stæhr K.J., 2009, Prediction of selectivity from morphological conditions: Methodology and a case study on cod (Gadus morhua). Fish. Res. 97, 59-71.

Herrmann B., Sistiaga M., Nielsen K.N., Larsen R.B., 2012, Understanding the size selectivity of red fish (Sebastes spp.) in North Atlantic trawl codends. J. Northw. Atl. Fish. Sci. 44, 1-13.

ICES, 2011, Report of the ICES-FAO Working Group on Fishing Technology and Fish Behaviour (WGFTFB), 9-13 May 2011, ICES CM 2011/SSGESST:11.

ICES, 2012, ICES Advice 2012, Book 3. ICES, Copenhagen.

Krag L.A., Herrmann B., Madsen N., Frandsen F., 2011, Size selection of haddock (Melanogrammus aeglefinus) in square mesh codends: A study based on assessment of decisive morphology for mesh penetration. Fish. Res. 110, 225-235. 
Manly B.F.J., 1997, Randomization, bootstrap and Monte Carlo methods in biology - Texts in statistical science. Chapman \& Hall.

Millar R.B., 1993, Incorporation of between-haul variation using boot strapping and nonparametric estimation of selection curves. Fish. Bull. 91, 564-572.

Millar R.B., Fryer R.B., 1999, Estimating the size selectivity of towed gears, traps, nets and hooks. Rev. Fish. Biol. Fish. 9, 89-116.

O'Neill F.G., Kynoch R.J., Fryer R.J., 2006, Square mesh panels in North Sea demersal trawls: separate estimates of panel and codend selectivity. Fish. Res.78, 333-341.

Pampoulie C., Danielsdottir A.K., 2008, Resolving species identification problems in the genus Sebastes using nuclear genetic markers. Fish. Res. 93, 54-63.

Power D.J., Ni I.H., 1985, Morphometric differences between golden redfish (Sebastes marinus) and beaked red fishes (S. mentella and S. fasciatus). J. North Atlant. Fish. Sci. 6, 1-7.

Sistiaga M., 2010, Selectivity studies in the Barents Sea bottom trawl gadoid fishery: Gear and methods. PhD thesis, University of Troms $\emptyset$.
Sistiaga M., Herrmann B., Larsen R.B., 2009, Investigation of the paired-gear method in selectivity studies. Fish. Res. 97, 196-205.

Sistiaga M., Herrmann B., Grimaldo E., Larsen R.B., 2010, Assessment of dual selection in grid based selectivity systems. Fish. Res. 105, 187-199.

Sistiaga M., Herrmann B., Nielsen K.N., Larsen R.B., 2011, Understanding limits to cod and haddock separation using size selectivity in a multispecies trawl fishery: an application of FISHSELECT. Can. J. Fish. Aquat. Sci. 68, 927-940.

Wienbeck H., Herrmann B., Moderhak W., Stepputtis D., 2011, Effect of netting direction and number of meshes around on size selection in the codend for Baltic cod (Gadus morhua). Fish. Res. 109, 80-88.

Wileman D.A., Ferro R.S.T., Fonteyne R., Millar R.B. (Eds.), 1996. Manual of methods of measuring the selectivity of towed fishing gears. ICES Coop. Res. Rep. No. 215.

Zuur G., Fryer R.J., Ferro R.S.T., Tokai T., 2001, Modelling the size selectivities of a trawl codend and an associated square mesh panel. ICES J. Mar. Sci. 58, 657-671. 